\title{
Incentives to innovate and the sources of innovation: the case of scientific instruments*
}

\author{
William Riggs ${ }^{\mathrm{a}}$ and Eric von Hippel ${ }^{\mathrm{b}}$ \\ January, 1992 \\ WP\# 3378-92-BPS \\ Revised March, 1993
}

Riggs, William and Eric von Hippel (1994), "The Impact of Scientific and Commercial Values on the Sources of Scientific Instrument Innovation," Research Policy 23 (July): 459-469.

* Our research on this paper has benefitted greatly from discussions with and advice from our colleagues Anne Carter, Dietmar Harhoff, Nathan Rosenberg and Stephan Schrader.

a Visiting Scholar, MIT Sloan School of Management, Cambridge, MA 02139

$\mathrm{b}$ Professor, MIT Sloan School of Management, Cambridge, MA 02139 


\begin{abstract}
$\underline{\text { ABSTRACT }}$
In this study we explore the relationship between the sources of innovation and incentives to innovate in a sample of 64 innovations related to Auger and Esca - two types of scientific instrument used to analyze the surface chemistry of solid materials. We find that innovations with high scientific importance tend to be developed by instrument users, while innovations having high commercial importance tend to be developed by instrument manufacturers. We also find that the ratio of user and manufacturer innovation affecting a given type of instrument can vary as a function of that instrument type's perceived scientific and commercial importance. Finally, we find that the scientific and commercial importance of innovations developed for Auger and Esca, and the frequency with which these have been developed, have varied significantly over time.
\end{abstract}




\section{Incentives to innovate and the sources of innovation: the case of scientific instruments}

\section{Introduction}

It has been shown that commercialized scientific instruments are often developed by the scientists who use them(von Hippel 1976). It has also been shown that users' and manufacturers' and suppliers' reasonable expectations for appropriating benefit from a given class of innovation can differ, and that such differences are associated with different levels of innovation on the part of such "functional" categories of innovator (von Hippel 1988). (See (Schmookler 1966, Mansfield 1968) for data on the more general finding that the rate of innovation is affected by expectations of innovation-related benefit.) Thus, when a product user's reasonable expectations of benefiting from a given innovation opportunity are higher than those of a product manufacturing firm, we would expect to find that the user would be more likely to innovate than would the manufacturer.

To this point, the link between incentives to innovate and the functional sources of innovation has only been explored at the level of entire categories of good (e.g., "scientific instruments," or "semiconductor process machinery.") In the present paper we take an important next step, and test the link between incentives to innovate and the sources of innovation at the level of individual innovations. We conduct this test in the field of scientific instruments. We first determine the functional sources of innovation in a sample of 64 major, commercially-manufactured innovations related to Esca and Auger - two related types of instruments used to study the chemistry of solid surfaces. We find that users of such instrumentation working in university, industry or government laboratories ("users") were the developers of $44 \%$ of these innovations, and that employees of scientific instrument manufacturering firms ("manufacturers") were the developers of $56 \%$.

We next explore user and manufacturer incentives to innovate in the case of each innovation. We begin by pointing out that users and manufacturers each value different attributes of scientific instrument innovations. Scientist-users seek reward in a sense of accomplishment and in the regard of peers with respect to that accomplishment (Merton 1957, Allen and Katz 1992). In contrast, manufacturers of scientific innovations seek reward in the form of monetary profit. We therefore obtain ratings for both the scientific and the commercial importance of each of 
these innovations. We find a very significant tendency for users to develop innovations that have high scientific importance, and for manufacturers to develop innovations that have high commercial importance - which strongly supports the hypothesized link between incentives to innovate and the sources of innovation. Finally, we report on variations over time in the scientific and commercial importances of innovations included in our sample, and on the frequency of user and manufacturer innovation over time.

In section 2 we describe the methods used in our empirical study of scientific instrument innovations. In section 3 we report on our study findings, and in section 4 we elaborate on some of the patterns found, and offer suggestions for further research.

\section{Sample and Methods}

Our study examines innovation patterns in two related types of scientific instrument, Auger Electron Spectroscopy and Electron Spectroscopy for Chemical Analysis (Esca). Our decision to focus on these two instrument types was dictated by two very practical considerations. First, one of the authors (W. Riggs) combines a background in innovation research with extensive prior professional experience in the use and manufacture of both Auger and Esca. Second, the fact that both instruments were developed relatively recently meant that most of the important contributors to innovation in the field are still professionally active, and able to provide us with rich, first-hand information on their activities.

Auger and Esca are used to analyze the chemical composition of solid surfaces. Prior to the development of Auger and Esca, information on the chemical composition of surfaces was typically obtained via indirect methods, such as reflectivity and contact angle measurement, or with methods with low surface specificity, such as multiple internal reflection infrared spectroscopy and $\mathrm{x}$-ray fluorescence. Auger and Esca instrumentation and techniques are a great improvement. They involve placing samples to be analyzed into a vacuum chamber and directing x-ray or electron beams onto the sample surface. Electrons emitted from the sample are collected and analyzed to identify and measure the chemical elements present in the top few atomic layers (Riggs and Parker 1975; Joshi, Davis and Palmberg 1975).

The first publications reporting on the potential analytical utility of Auger and Esca methods appeared in the 1950's (Lander 1953; Siegbahn 1954). Esca and Auger instruments were first manufactured commercially in 1969, and by 
1970 several companies had entered the field. Today these instruments are used in many hundreds of industrial and university labs worldwide. Applications range from the study of metals, catalysis, adhesion and corrosion to studies of the electronic behaviors of materials. In 1992, total world sales for Auger and Esca instruments combined was approximately $\$ 100$ million.

Our sample of Auger and Esca innovations contains a total of 64 innovations. Two of these are the Auger and Esca instruments as initially developed and the remaining 62 are all of the succeeding improvement innovations we were able to identify that met two criteria. First, they offered a major improvement relative to previous best practice in Auger and Esca and second, they were produced commercially by equipment manufacturers prior to 1988. (Some of the innovations in our sample were superceded by later improvements, and so not all have remained in production to the present day.) Types of innovations meeting these criteria included improvements to the hardware and software of the instruments themselves, improvements to instrument inputs, such as improved sample handling, and improvements to instrument outputs, such as data analysis software. Types of innovations not meeting these criteria, and therefore not included in our samples were technique-only innovations, process innovations, innovations not commercialized, and very recent innovations. Although the latter types of innovations are clearly important, excluding them from our sample is conservative with respect to testing the primary hypothesis being explored in this paper - that users will tend to develop scientifically important innovations, and that manufacturers will tend to develop commercially important ones.

Our sample (table 1) of major innovations was identified via a two-step process. First we reviewed both the scientific literature and the commercial product literature involving Auger and Esca, and generated a preliminary list of 50 innovations meeting our criteria. Next, we asked experts from the Auger and Esca user and manufacturer communities to review the list we had assembled, and to suggest additions and deletions. The result of this procedure was the selection of 29 major improvements to Auger, and 33 major improvements to Esca that met our sample selection criteria. Some of these innovations were of value to essentially the total user community, while others were of interest to only a subset. For example, an innovation enabling users to examine the surfaces of materials that have been freshly fractured under vacuum is of major importance to only some users. Also, some of the innovations were completely novel, and others proved to 
have been adapted from other fields of instrumentation in a pattern of interinstrument diffusion identified by Rosenberg (1992). For example, significant improvements to the electron guns used in Auger were often derived from improvements initially developed for the electron guns used in scanning electron microscopes. 
Table 1A: Major improvements to Auger from 1953 through 1987

First Auger Electron Spectrometer (Auger) (1953, Lander, Bell Labs)

$\underline{\text { New Functional Capabilities }}$

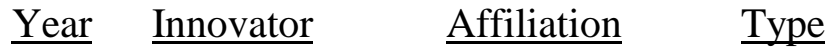

1. Analysis as a function of depth

$\begin{array}{ll}1969 & \text { Marcus } \\ 1969 & \text { Stein, et. al. } \\ 1970 & \text { McDonald } \\ 1977 & \text { Hobson } \\ 1982 & \text { Landolt }\end{array}$

Rockwell

user

3. Specimen fracture device

2. Scanning auger microscopy

4. UHV sample transfer

1982 Landolt

U. Minnesota user

Rockwell user

NRC-Canada user

5. Spin polarization detector

ETH-Zurich

user

Convenience or Reliability

Improvement

\begin{tabular}{|c|c|c|c|}
\hline 6. Multi-sample carousel & 1969 & Weber & PHI \\
\hline 7. Compilation of standard spectra & 1972 & Palmberg & PHI \\
\hline $\begin{array}{l}\text { 8. Simultaneous sputtering and Auger } \\
\text { analysis }\end{array}$ & 1972 & Palmberg & PHI \\
\hline 9. Multiplexer & 1972 & McDonald & PHI \\
\hline 10. Esca/Auger two-analyzer instrument & 1975 & Palmberg & PHI \\
\hline 11. Quantitative sensitivity factors & 1976 & Palmberg & PHI \\
\hline $\begin{array}{l}\text { 12. Microprocessor control of beam } \\
\text { column }\end{array}$ & 1976 & McDonald & PHI \\
\hline $\begin{array}{l}\text { 13. Esca/SAM double-pass cylindrical } \\
\text { analyzer }\end{array}$ & 1977 & Palmberg & PHI \\
\hline 14. Eucentric motion specimen stage & 1977 & unknown & JEOL \\
\hline 15. Differentially pumped ion gun & 1977 & Palmberg & $\mathrm{PHI}^{\mathrm{a}}$ \\
\hline $\begin{array}{l}\text { 16. Full computer control of instrument } \\
17 \text { Multinoint nrofiling }\end{array}$ & $\begin{array}{l}1980 \\
1981\end{array}$ & $\begin{array}{l}\text { McDonald } \\
\text { Gerlach }\end{array}$ & $\begin{array}{l}\text { Perkin-Elmer } \\
\text { Perkin-Elmer }\end{array}$ \\
\hline 17. Multipoint profiling & 1981 & Gerlach & Perkin-Elmer \\
\hline
\end{tabular}

$\underline{\text { Sensitivity, Resolution or Accuracy Improvement }}$

$\begin{array}{lllll}\text { 18. Auger based on 4-grid LEED optics } & 1967 & \text { Weber } & \text { U. Minnesota } & \text { user } \\ \text { 19. First derivative spectra } & 1968 & \text { Harris } & \text { GE Labs } & \text { user } \\ \text { 20. Cylindrical mirror analyzer } & 1969 & \text { Palmberg } & \text { Rockwell } & \text { user } \\ \text { 21. Double-pass cylindrical analyzer } & 1973 & \text { Palmberg } & \text { PHI } & \mathrm{mfr} \\ \begin{array}{l}\text { 22. Coaxial electron gun scanning } \\ \text { Auger }\end{array} & 1973 & \text { McDonald } & \text { PHI } & \mathrm{mfr} \\ \begin{array}{l}\text { 23. Rastered ion gun } \\ \text { 24. Field emission electron gun }\end{array} & 1974 & \text { Taylor } & \text { Varian } & \mathrm{mfr} \\ \begin{array}{l}\text { 25. Spherical capacitor analyzer for } \\ \text { AES }\end{array} & 1975 & \text { Pocker \& Haas } & \text { WPAFB } & \text { user } \\ \text { 26. Lanthanum hexaboride filament } & 1976 & \text { Anderson } & \text { VG } & \mathrm{mfr} \\ & & \text { McDonald } & \text { PHI } & \mathrm{mfr}\end{array}$


27. Multichannel detector

28. Magnetic objective lens

29. Zalar rotation
1980 Anderson \& Latham

1980 Gerlach

1985 Zalar
VG $\quad \mathrm{mfr}$

Perkin-Elmer $\mathrm{mfr}$ IEVT-Ljubljana user

TOTAL Auger major improvement innovations $=29$

${ }^{a} \mathrm{PHI}$ was acquired by Perkin-Elmer in 1977. Subsequent innovations due to this manufacturer are listed under the parent corporation name.

Table 1B: Major improvements to Esca from 1953 through 1987

\section{First Esca Spectrometer (1954, Siegbahn, University of Uppsala)}

$\underline{\text { New Functional Capabilities }}$

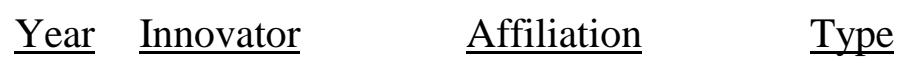

30. Hot/cold stages

31. Angle resolved Esca

32. Ultra-high vacuum Esca

33. Inert atmosphere sample transfer

34. S-curve background subtraction

35. UHV sample preparation chamber

36. Esca depth profiling

37. Auger parameter

38. Direct imaging

39. Element mapping
1967 Siegbahn

1971 Fadley

1971 Latham

1971 Tolman

1972 Shirley

1972 Latham

1974 Riggs

1977 Wagner

1981 Turner

1983 Gurker, et.al.
Univ Uppsala user

U. Goteborg user

VG $\mathrm{mfr}$

DuPont user

U.C.Berkeley user

VG $\mathrm{mfr}$

DuPont mfr

Shell Dev. user

Oxford Univ. user

TU-Vienna user

Convenience or Reliability Improvement

40. Rapid sample introduction

41. Computer control of instrument

42. Curve fitting

43. Quantitative sensitivity factors

44. Multiple anode x-ray source

45. Satellite subtraction

46. Compilation of standard spectra

47. UHV sample interlock

48. Principle component analysis for Esca spectra

49. Automated Esca depth profiling

50. Tougaard background correction

51. Automatic peak identification
1969

1969

1969

1972

1973

1974

1977

1978

1979 Garenstrom

1981 Riggs, et. al.

1982 Tougaard

1986 Barth/Kelly
Varian

Varian

Varian

Shell Dev.

VG

McPherson

Perkin-Elmer

VG

GM Labs

Perkin-Elmer $\quad \mathrm{mfr}$

Odense Univ. user

Surface Sci. Insts. $\mathrm{mfr}$ $\mathrm{mfr}$

$\mathrm{mfr}$

$\mathrm{mfr}$

user

$\mathrm{mfr}$

$\mathrm{mfr}$

$\mathrm{mfr}$

$\mathrm{mfr}$

user 
$\underline{\text { Sensitivity, Resolution or Accuracy Improvement }}$

52. X-ray monochrometer

53. Electric sector analyzer

54. Multichannel detector

55. High-intensity $x$-ray source

56. Gold deposition method for charge

correction

57. Band pass analyzer

58. Rotating anode $\mathrm{x}$-ray source

59. Flood gun for charge

compensation

60. Dispersion compensation analyzer

61. X-ray line deconvolution

62. Focussed X-ray source
1966 Siegbahn

1967 Siegbahn

1967 Siegbahn

1968 Helmer

197

Hnatowich, et. al.
Univ Uppsala user

Univ Uppsala user

Univ Uppsala user

Varian

$\mathrm{mfr}$

user

1971 Lee DuPont mfr

1971 Siegbahn Univ Uppsala user

1972 Huchital \& Perkin-Elmer mfr

McKeon

1972 Hammond, et. al. Hewlett-Packard mfr

1974 Ebel TU-Vienna user

1977 Chaney \& Kelly Surface Sci. Insts. mfr

TOTAL Esca major improvement innovations $=33$ 
Information presented in this paper was collected from several sources. Semistructured interviews were conducted (face-to-face and via telephone) with those who had developed and/or had first-hand knowledge of the development of the innovations in our sample. Additional information was collected from scientific publications, and from manufacturers' published product literature. All information from interviews that we report has been cross-checked with two or more experts to insure accuracy.

In our study, we collected information on the source of each innovation in our sample, and information on the scientific and commercial importance of each. To obtain information on the source of each innovation, we explored the history of each, and coded the source of each as either user-developed or manufacturerdeveloped. "Users" were practicing scientists who utilize Esca and/or Auger in their research, and who are not employed by manufacturers of Auger or Esca equipment. (Fifteen of the innovations in our sample were developed by users employed by universities, 9 by users employed by corporate research labs devoted to fundamental research, and 4 by users employed by government laboratories.) "Manufacturers" were employees of firms that manufacture Auger and/or Esca systems and/or related accessories and components. Our coding of an innovation as being developed by a user or a manufacturer depended on who built the first hardware or software embodiment of the innovation that was used to produce publishable results. If a user was first, the innovation was coded as userdeveloped; if a manufacturer was first, it was coded as manufacturer-developed.

Next, we asked five experts drawn from the user and the manufacturer communities to rank each innovation in our sample in terms of scientific and commercial importance on a scale of 1 - 5. Each expert was asked to rate each of the innovations on a five point scale for commercial importance and for scientific importance. Given the unreliability of retrospective data, we had no realistic expectation of determining what the expectations of potential innovators would have been on these matters at the time of the innovations. Therefore, we asked our experts to judge what these importances had in fact turned out to be over time, and assumed that innovators' expectations on these matters at the time of the innovations were at least somewhat correlated with actual outcomes.

Interrater reliability was assessed for the two measures (scientific importance and commercial importance) by calculation of Cronbach's alpha. The values were 0.80 for the judgement of scientific importance and 0.71 for commercial importance. This reflects an acceptable level of reliability for these 
measures. In addition, we found no reason to segregate the rating scores provided by scientists from those provided by instrument firm employees.

After the ratings were complete, each expert was asked to describe what he had in mind with respect to the "scientific importance" and "commercial importance" of the innovations he ranked on these variables. Four of the five responded to this open-ended question, and their responses showed a high degree of consistency on the matter. All viewed commercial importance as meaning impact on manufacturers' sales, and all viewed scientific importance as having to do with the enabling or achievement of scientific advance. Representative quotes from the experts may help to convey the flavor of their responses.

Scientific Importance means: "...contributes to enabling scientific advance"; "...opens up access to new levels of scientific information";

"...number and quality of publications resulting from an innovation";

"...whether the innovation furthered understanding...".

Commercial importance means: "...the effect on manufacturers' product sales"; "...what sells instruments"; "...recognition that it would be useful"; "...extent used on a routine basis to solve problems."

The distributions of the scientific and commercial importance scores generated by our raters were approximately normal, and so we use parametric statistics in our analyses of findings.

\section{3: Findings}

Our findings with respect to the sources of innovation and commercial and scientific importance are shown in figure 1 and table 2 . As can readily be seen, we find significant support for the hypothesis that innovations having high scientific importance tend to be developed by users $(p<0.001)$, while innovations with high commercial importance tend to be developed by manufacturers $(\mathrm{p}<0.01)$.

Figure 1: Scatter plot of ratings of user and manufacturer-developed innovations on scientific and commercial importance 


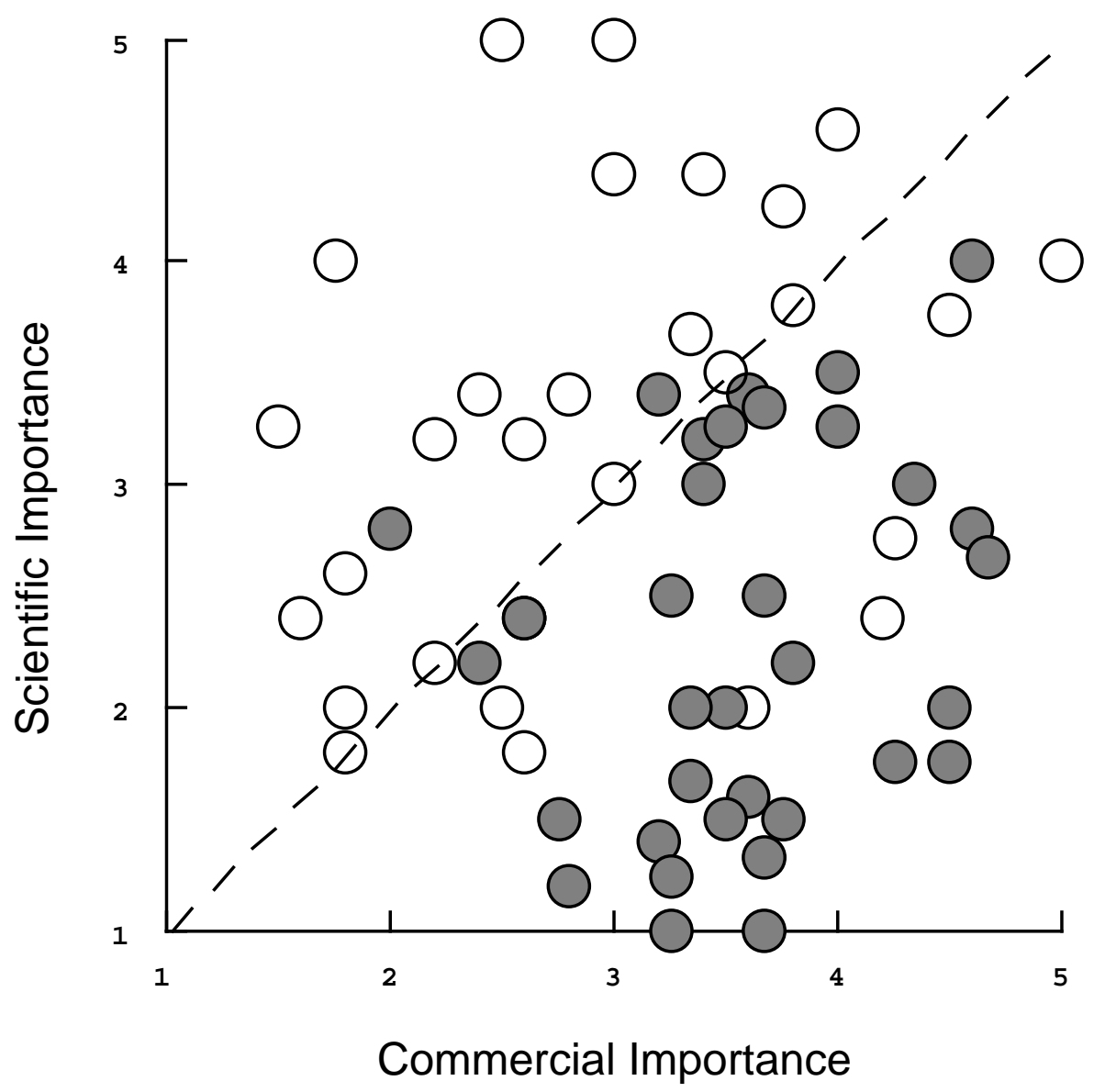

O User Innovation

○ Manufacturer Innovation

Table 2: Mean scientific and commercial importances of user and manufacturer innovations

\begin{tabular}{|c|c|c|}
\hline Number of & Mean Scientific & Mean Commercial \\
\hline Innovations & $\underline{\text { Importance }}^{\mathrm{a}}$ & $\underline{\text { Importance }}^{\mathrm{b}}$ \\
\hline 28 & 3.28 & 2.94 \\
\hline 36 & 2.30 & 3.50 \\
\hline
\end{tabular}

a User-Manufacturer difference significant at $\mathrm{p}<0.001$

$\mathrm{b}_{\text {User-manufacturer difference significant at } \mathrm{p}<0.01}$ 
Our data showed no correlation between the measures of scientific importance and commercial importance $(r=0.064$, n.s. $)$. This is a desirable state of affairs from the point of view of the clarity of our findings, and we see two reasons for it. First, the measures of scientific importance and commercial importance used by our raters appear to us to be completely independent. For example, the criteria raters said they used to determine the scientific importance of an innovation focussed on the scientific importance of the innovation "itself" as reflected in the scientific interest and importance of the publication(s) that initially presented and discussed it. It did not include any consideration of how many or few users found an innovation useful - a consideration that would have created a link between scientific and commercial importance measures.

Second, as our interviews made clear, it is reasonable to treat the incentives of the innovators in our sample as being exclusively focused on only one of the two measures of innovation importance. While user innovators might have financial motivations in addition to scientific ones, the only realistic route to financial rewards for them - barring abandoning user status by starting or joining an instrument manufacturing firm - was to make and report on scientific achievements, which might in turn lead to salary increases, promotions, etc.. According to both our instrument company and our user interviewees, user innovators almost never gained direct financial benefit from their instrument innovations when these were commercialized by instrument firms. Royalties were never paid, and paid consulting arrangements were quite rare. Similarly, an exclusive focus on innovation-related profit seems to be a good measure of manufacturer motives in our sample. Scientific instrument manufacturers do employ scientists who are not indifferent to the rewards to be had from publishing, and sometimes they do publish. However, the firms we studied are aware of the importance of priority in publication to their scientist customers. They do not seek to compete with them, and do take pains to acknowledge their priority as appropriate.

\section{Type of Innovation Improvement and Innovation Source}

The types of improvement offered by the innovations in our sample varied widely. We examined the sample to see if we could make any general observations about the nature of improvements that tended to receive a high 
scientific or commercial importance rating. As is shown in table 3, we found that innovations that allowed users to do qualitatively new types of things tended to

Table 3: Source of innovations by nature of improvement effected

Type of improvement Innovation developed by: Mean Importance provided by innovation $\quad \underline{\text { Uuser }} \underline{\text { User Mfr }} \underline{\text { Total Scientific } \text { Comml }}$

\begin{tabular}{|c|c|c|c|c|c|}
\hline $\begin{array}{l}\text { (1) New functional } \\
\text { capability }\end{array}$ & $82 \%$ & 14 & 3 & 17 & 3.33 \\
\hline $\begin{array}{l}\text { (2) Convenience } \\
\text { or reliability } \\
\text { improvement }\end{array}$ & $13 \%$ & 3 & 21 & 24 & 2.28 \\
\hline $\begin{array}{l}\text { (3) Sensitivity, } \\
\text { resolution } \\
\text { or accuracy } \\
\text { improvement }\end{array}$ & $48 \%$ & 11 & 12 & 23 & 2.74 \\
\hline
\end{tabular}

Total 64

have high scientific importance, and that users tended to develop these. An example of such a "new functional capability" innovation is the spin polarization detector for Auger spectrometers developed by Landolt. This device makes it possible to image and analyze magnetic domains with sub-microscopic dimensions, something that could not be done previously. Innovations that had the effect of increasing the convenience or reliablility of an instrument tended to have higher commercial than scientific importance, and were usually developed by manufacturers. An example of such an innovation was the computerization of the electron beam adjustments involved in the operation of Auger instruments, which removed the need for literally dozens of manual adjustment controls. This innovation made the instrument significantly easier to operate, but did not at all change the type or quality of measurements that could be made.

A third group of innovations that improved 3 key performance parameters of the instrument - sensitivity, resolution and accuracy - were developed by both users and manufacturers. The scientific and commercial importances of 
innovations in this category varied. Those having a higher scientific importance tended to be developed by users ( $\mathrm{p}<0.05$ ), but there was no statistically significant link between commercial importance and type of innovator in the category. Sensitivity is related to the smallest amount of a material that the instrument can detect and measure in a given amount of time, while resolution has to do with the fineness of detail that can be observed. Accuracy has to do with how well the locations of features in the data can be determined. An example of an innovation that improved instrument resolution was the replacement of tungsten filaments in scanning Auger instruments with filaments made of lanthanum hexaboride.

Type of Instrument and Innovation Source

It seems reasonable that the scientific and commercial importance of types of scientific instruments will differ, just as individual improvement innovations do. If so, it may be that the proportion of user vs manufacturer innovation affecting a given type of instrument will vary as a function of the overall scientific and commercial importance of that type.

Table 4: Relationship between scientific and commercial importance of innovations and proportion of user vs manufacturer innovations

a: Mean importance ratings of innovations

Innov developed by: Mean Importance

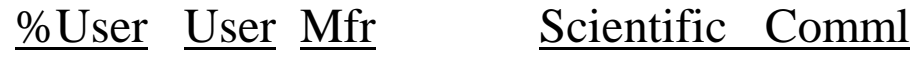

$\begin{array}{lccccc}\text { Esca } & 50 \% & 17 & 17 & 2.90 & 2.98 \\ \text { Auger } & 37 \% & 11 & 19 & 2.54 & 3.57\end{array}$

b: Overall importances of Auger and Esca as judged by expert panel

Innov developed by: Overall Importance 


\section{\%User User Mfr $\quad$ Scientific Comml}

$\begin{array}{lccccc}\text { Esca } & 50 \% & 17 & 17 & 4.00 & 3.75 \\ \text { Auger } & 37 \% & 11 & 19 & 2.75 & 3.75\end{array}$

We tested this idea with respect to Auger and Esca in two ways. First, we used the distribution of the scientific and commercial importances of all the innovations in our Esca and Auger samples as a proxy for the overall scientific and commercial importance of each of these instrument types. As can be seen reflected in the means in table $4 \mathrm{a}$, the scientific importances of the innovations affecting Esca were higher than for Auger but the difference is not statistically significant $(\mathrm{p}=0.15)$, while the commercial importance of Esca innovations was significantly lower than that of Auger $(\mathrm{p}<0.01)$. These differences are in the direction we would expect, given the substantially greater proportion of innovations developed by users found in our Esca sample. Second, we asked our raters to directly compare Esca and Auger as instrument types on overall scientific and commercial importance on a scale of 1 to 5. As shown in table 4b, the results are also in a direction consistent with a greater proportion of user innovation in Esca, but in this case because the scientific importance rating for Esca is substantially greater than that of Auger, while the commercial importance ratings do not differ.

It would be useful to test the possible relationship between scientific vs commercial importance of instrument types and the locus of innovation on additional types of instrument, but we do not currently have the data to do this. Von Hippel (1976) found an average of $77 \%$ user innovation in a study of the sources of innovation affecting four other types of scientific instruments (the gas chromatograph, the nuclear magnetic resonance spectrometer, the ultraviolet absorption spectrophotometer, and the transmission electron microscope), but did not collect data on the scientific and commercial importance of the innovations studied. If the proportion of user vs manufacturer innovation is indeed related to an instrument type's perceived overall scientific and commercial importance, the locus of innovation data suggests that innovators active at the time saw the overall scientific importance of the four instrument types studied by von Hippel as higher, and/or the commercial importance as lower than did the innovators active in the development of Auger and Esca. 
Variations in Innovation Frequencies and Importances over Time

Figure 2 shows patterns in the importance and frequencies of Auger and Esca innovations over time, and also shows combined sales volumes for Auger and Esca instruments over time. In figure $2 \mathrm{a}$ we see that the scientific importance of the innovations that have been developed in Auger and Esca has dropped off sharply over time. Since users are motivated by scientific importance, it is reasonable that we also see a corresponding drop in the frequency of user innovation (figure $2 b$ ). While the reason for the drop in scientific importance cannot be documented with the data available to us in this study, we speculate that it could be due to the capabilities of Auger and Esca techniques having approached their physical limits in important ways, and/or due to the development of substitutes for some Auger and Esca measurements. There is some evidence in support of both of these possibilities. For example, it is difficult to further improve the spatial resolution of Auger because of apparently intractable limitations on the precision with which one can focus electron beams. Also, a partial substitute for scanning Auger has been developed which offers much better spatial resolution than Auger - the scanning tunneling microscope (STM).

Figure $2 \mathrm{a}$ also shows that the commercial importance of Esca and Auger innovations developed over time has remained reasonably steady, and that sales (figure 2c) and R\&D budgets have gone up (in constant dollars) during the period studied. (Industry interviewees inform us that manufacturer R\&D budgets tend to be a constant percentage of sales, and say that these have gone up over the years.) Nonetheless, the frequency of innovations by Auger and Esca manufacturers has dropped over time (figure $2 \mathrm{~b}$ ). This is a puzzle requiring further exploration. Candidate explanations that have been put forward include a rise in $\mathrm{R} \& \mathrm{D}$ costs per innovation as instrument capabilities approach physical limits and as instrument complexity rises, and a shift of manufacturer R\&D funds Figure 2: Changes in innovation importance, frequency, and sales over time 

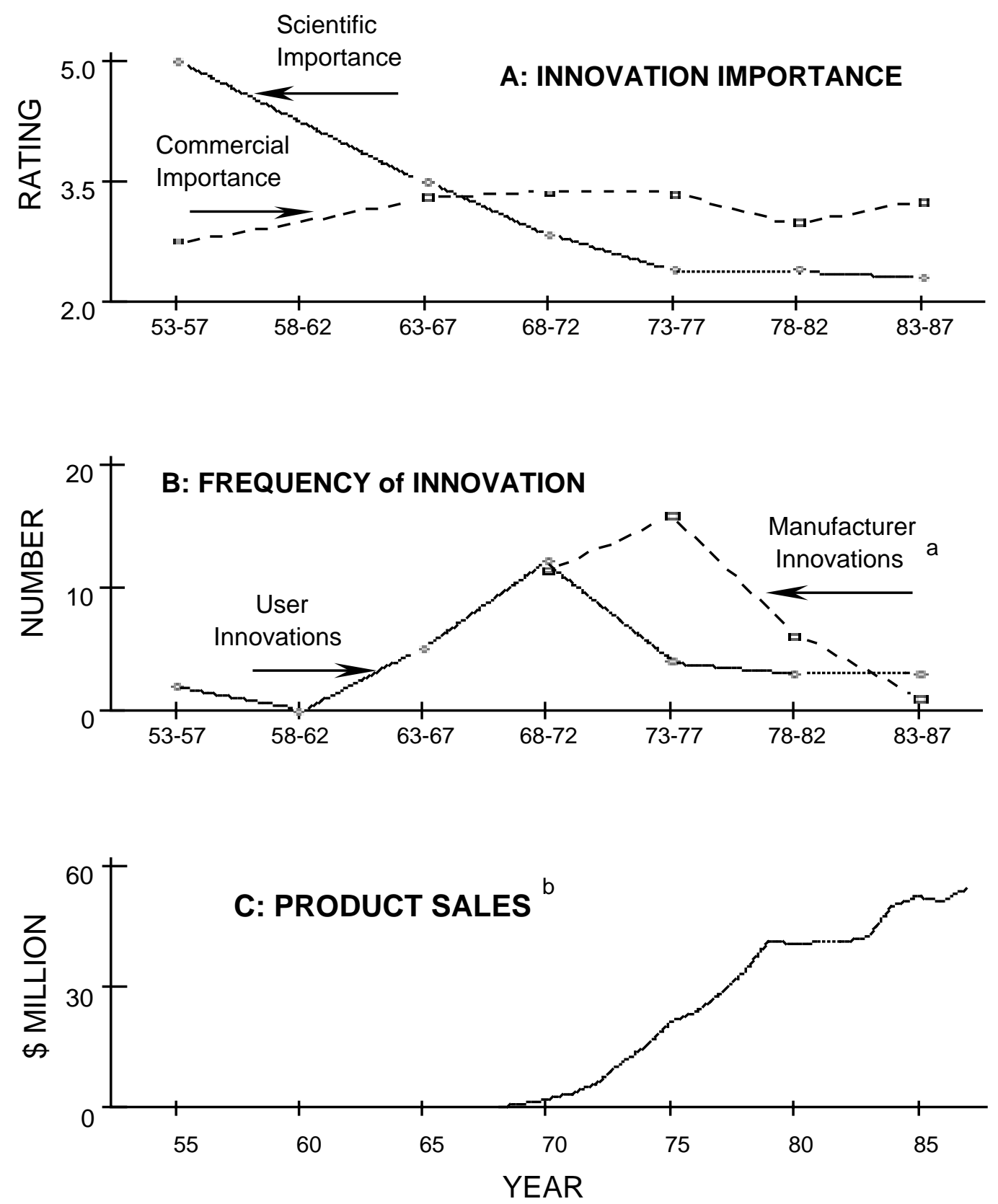

a The first manufacturer innovations were commercialized in 1969.

b Constant dollars, base period 1982-4 (U.S. Bureau of the Census, 1992). Sales data were assembled from three sources: Strategic Directions International (1991); Frost \& Sullivan (1986); a leading manufacturer of Auger and Esca. Auger and Esca sales data cannot be easily separated, and so are combined in figure 2c, because manufacturers have sold instruments with both Esca and Auger mounted on a single platform in recent years. 
from product to process innovation as the number of units produced per year rises. It has also been suggested that as the fields mature, development effort shifts toward emphasis on user convenience and speed via software developments embedded in the instruments and not identified as individual innovations. However, neither we nor our expert interviewees find these explanations fully satisfactory on the basis of the anecdotal data available.

\section{4: Discussion}

In this study of scientific instrument innovation, we have been able to show very strong links between appropriable innovation benefit, the sources of innovation and the types of innovation that are developed. We have argued that these very clear patterns are obtainable because the benefits sought by innovating users and manufacturers of scientific instruments are of two different, nonconvertible types. As a consequence, a major source of noise in other studies of the link between the sources of innovation and appropriable innovation benefit variation in the outcome of competitions among different classes of would-be innovator for the same pool of benefits - has been avoided.

Our focus on "the" source of innovation in the body of this study has given short shrift to patterns of joint user-manufacturer involvement in the innovation process. The measure of the source of innovation used in this study was based on who - user and/or manufacturer - actually built the first software or hardware embodiment of an innovation that produced published results. This measure showed no instances of joint user-manufacturer innovation because no case in our sample involved a jointly-built prototype of an innovation. However, the development of scientific instrument innovations does involve extensive information transfer, and occasionally more substantial interaction, between users and manufacturers.

Information transfer between instrument users and manufacturers occurs in a number of ways. Instrument manufacturers conduct market surveys to assess user needs. They also send engineers and technically trained sales people to conferences and to the labs of leading users to get information on leading-edge needs and prototype user solutions to those needs. Sometimes, they even send a staff member on a research sabbatical to a user lab for this same reason. Manufacturers often hire scientists and engineers with user experience to work in their development labs, and these employees also transfer information on user needs and solutions to the manufacturer. Also, some maintain in-house 
demonstration laboratories where customers may come and conduct measurements on their samples using the latest equipment - an additional way for user and manufacturer personnel to work closely together and transfer innovation-related information.

Joint involvement in an innovation project can serve both user and manufacturer interests well. Typically, the reward to the user under these circumstances is access to the first machine produced that embodies the innovation. The user thus gains lead time that allows him to reap the (prioritybased) scientific innovation benefits associated with the innovation even as the manufacturer reaps the commercial benefits. Nonetheless, substantial interaction between user and manufacturer during innovation development was found in only 4 cases in our sample. These cases showed somewhat closer scientific and commercial importance scores than did the remainder of the sample. (The average difference between the scientific and commercial importance ratings of the four innovations that showed some joint activity is 0.69 , compared to 1.14 for the remainder of the sample.)

Suggestions for further research

Our finding that users tend to develop innovations having significant scientific importance, while manufacturers tend to develop innovations having significant commercial importance is compatible both with a pattern of innovation decision-making in which each type of innovator focuses on its type of importance only, and with a pattern involving some sort of interdependence between user and manufacturer decision-making with respect to innovation. We think that the latter possibility is worthy of further research. Some interdependence is likely in that manufacturers undertake development projects based in large part on expressions of interest by users - and users tend to ask manufacturers to develop improvements that they would like to have, but which they do not think worth developing on their own. There may also be a pattern in which manufacturers encourage users to innovate in areas that they see as having too little commercial importance to merit a manufacturer-only development project.

It would also be useful, we think, to gain a better understanding of why the scientific importance of innovations drops over time. It may be that when a new 
technique such as Auger or Esca is developed, a number of obviously-important opportunities for scientific advance are opened up, and that these are quickly "mined out" in the first few years. In a similar vein, it would be useful to understand why the rate of innovation by manufacturers drops over time, even though sales are increasing. This is not an outcome congruent with the "extent of the market" argument made by Schmookler (1966). 


\section{$\underline{\text { References }}$}

Allen, Thomas J., and Ralph Katz (1992) "Age, Education and the Technical Ladder", IEEE Transactions on Engineering Management, 39:3 pp. 237-45.

Brundle, Richard and Winston Roberts (1973), Chem Phys Letters, 18 p. 380.

Frost \& Sullivan (1986), "Analytical Instrumentation Market in the U.S.", Report A1593.

Joshi, Anne, Lawrence E. Davis and Paul W. Palmberg (1975), "Auger electron spectroscopy," in Czanderna, A. W. (ed.), Methods of Surface Analysis, New York: Elsevier Scientific Publishing Company, pp. 159-222.

Lander, J. J. (1953), "Auger peaks in the energy spectra of secondary electrons from various materials," Physical Review, 91, pp. 1382-1387.

Mansfield, Edwin (1968), Industrial Research and Technological Innovation: An Econometric Analysis, New York: W. W. Norton \& Company.

Merton, Robert K. (1957), Social Theory and Social Structure, 2nd ed., Glencoe, Ill.: Free Press.

Riggs, William M. and Martin J. Parker (1975), "Surface analysis by x-ray photoelectron spectroscopy," in Czanderna, A. W. (ed.), Methods of Surface Analysis, New York: Elsevier Scientific Publishing Company, pp. 103-158.

Rosenberg, Nathan (1992) "Scientific instrumentation and university research", Research Policy 21: 4, pp. 381-90

Schmookler, Jacob. Invention and Economic Growth. Cambridge, Mass.: Harvard University Press, 1966.

Siegbahn, Kai, D. Hammond, H. Fellner-Feldegg and E. F. Barnett (1972), Science 176 pp. 245. Strategic Directions International (1991), Report on the Worldwide Analytical Instrument Industry, Los Angeles, p E-1.

U.S. Bureau of the Census (1992), Statistical Abstract of the United States:1992 (112th edition), Washington D.C., Table 737.

von Hippel, Eric (1976) "The Dominant Role of Users in the Scientific Instrument Innovation Process." Research Policy 5, no.3 pp 212-39.

von Hippel, Eric (1988) The Sources of Innovation , New York: Oxford University Press. 